\title{
Transmutation Strategy Using Thorium-Reprocessed Fuel ADS for Future Reactors in Vietnam
}

\author{
Thanh Mai Vu and Takanori Kitada \\ Division of Sustainable Energy and Environmental Engineering, Graduate School of Engineering, Osaka University, \\ 2-1 Yamadaoka, Suita-shi, Osaka 565-0871, Japan
}

Correspondence should be addressed to Thanh Mai Vu; m-vu@ne.see.eng.osaka-u.ac.jp

Received 30 May 2013; Revised 18 July 2013; Accepted 18 July 2013

Academic Editor: Arkady Serikov

Copyright (C) 2013 T. M. Vu and T. Kitada. This is an open access article distributed under the Creative Commons Attribution License, which permits unrestricted use, distribution, and reproduction in any medium, provided the original work is properly cited.

\begin{abstract}
Nuclear power is believed to be a key to the energy security for a developing country like Vietnam where the power demanding increases rapidly every year. Nevertheless, spent nuclear fuel from nuclear power plants is the source of radiotoxic and proliferation risk. A conceptual design of ADS utilizing thorium fuel as a based fuel and reprocessed fuel as a seed for nuclear waste transmutation and energy production is proposed as one of the clean, safe, and economical solutions for the problem. In the design, 96 seed assemblies and 84 blanket assemblies were inserted into the core to make a heterogeneous subcritical core configuration. Introducing thorium fuel into the core offers an effective way to transmute plutonium and minor actinide (MA) and gain energy from this process. Transmutation rate as a function of burnup is estimated using MCNPX 2.7.0 code. Results show that by using the seed-blanket designed ADS, at $40 \mathrm{GWd} / \mathrm{t}$ burnup, $192 \mathrm{~kg}$ of plutonium and $156 \mathrm{~kg}$ of MA can be eliminated. Equivalently, $1 \mathrm{GW}_{\text {th }}$ ADS can be able to transmute the transuranic (TRU) waste from $2 \mathrm{GW}_{\text {th }}$ LWRs. 14 units of ADS would be required to eliminate TRUs from the future reactors to be constructed in Vietnam.
\end{abstract}

\section{Introduction}

Demand for power is rising as Vietnam's economy expands. Electricity demand growth has been $14 \%$ per annum and is expected to be $15 \%$ per annum by 2015 and then slowing by 2020 , though other figures suggest $10 \%$ per annum. In order to improve the energy security, the government has approved the nuclear power development plan in Vietnam. Due to the plan, 2000 MWe nuclear power plant at Phuoc Dinh in the Ninh Thuan province should be online by 2020. A further 2000 MWe was planned at Vinh Hai nearby, followed by a further 6000 MWe by 2030. A high demand scenario would give 8000 MWe in 2025 and 15,000 MWe (10\% of total) in 2030 at up to eight sites in five provinces [1]. As demonstrated in detail later, from 2025 with 8000 MWe, about 170 tons of spent fuels (of which 3 tons is TRUs and long-life fission products (LLFFs)) is produced every year. It will extend to 120 tons of TRUs and LLFFs after 40 years of operation. In general, the spent nuclear fuel (SNF) is cooled in the water pools where the short half-life isotopes decay to safer level and decay heat drops; then, it can be stored at "dry" facilities.
Thus, reducing the amount of waste and minimizing the amount of radiation release to the environment are always an issue. With inherent safety feature and waste transmutation potential and capability of converting fertile fuel to fissile fuel without exposing the radiotoxic material to the environment [2], accelerator-driven system (ADS) which helps to burn TRU waste from spent fuel and produce energy at the same time can be a good candidate for the next few decades technology in Vietnam.

Thorium with its abundance is gaining a considerable attention as the fuel candidate to replace uranium fuel. When choosing the based fuel for the system, taking into account the ability of eliminating large amount of TRU waste since the production of these elements in thorium cycle is significantly reduced compared with the uranium cycle and energy gaining from this process, thorium is an appropriate candidate to be the based fuel in the ADS system. To start the fission reaction, reprocessed fuel $(\mathrm{Pu}+\mathrm{MA})$ is loaded into the core as seed and thus transmuted.

In this paper, conceptual designs of ADS for transuranic waste transmutation and power generation utilizing thorium 


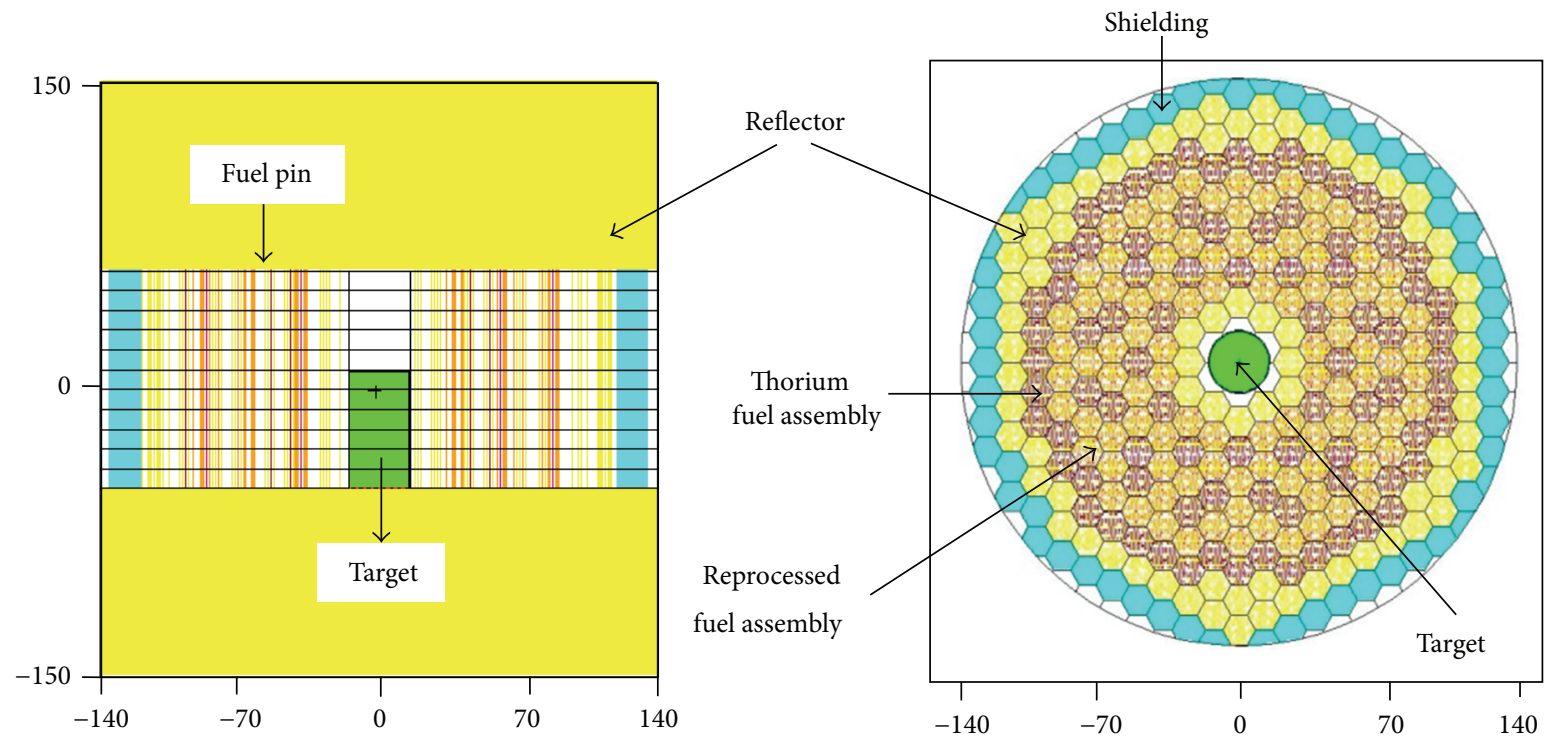

FIGURE 1: Vertical and horizontal sectional views of the seed-blanket ADS design (scale is given in $\mathrm{cm}$ ).

blanket and reprocessed fuel as a seed are proposed. The ADS configuration and the calculation code are described in Section 2. Calculation results and the elimination strategy for TRU are discussed in Section 3. Finally, summarizing the results, conclusions are remarked in Section 4.

\section{Calculations}

2.1. Seed and Blanket Thorium-Reprocessed Fuel ADS. The model of ADS used in this simulation was conducted from the typical fast neutron spectrum, lead-bismuth acceleratordriven transmutation system in Trellue research [3]. Neutrons are produced from the spallation reaction by bombarding $1 \mathrm{GeV}$ proton beam into the LBE cylindrical target. In the subcritical core, the fuel rods are introduced in the oxide form and contained in hexagonal assemblies. 180 fuel assemblies are loaded into the cylindrical core of $140 \mathrm{~cm}$ radius. However, instead of loading the whole core with reprocessed fuel as in original design, in this study, 96 seed assemblies of reprocessed fuel and 84 blanket assemblies of thorium fuel were inserted into individual regions. This heterogeneous approach will help to simplify the fuel assembly fabrication and in-core fuel management. By spatially separating the fertile and fissile materials, ideally, there would be no competition for neutron absorption between them; thus, the capture rate in fertile fuel would be optimized, and ${ }^{233} \mathrm{U}$ conversion ratio in the blanket could be enhanced. The breeding ${ }^{233} \mathrm{U}$ from thorium will compensate the burnt TRUs in the reprocessed fuel, thus reducing the reactivity swing. The thorium blanket assemblies are placed at the periphery of the core in order to improve the neutron economy. Sodium is employed as coolant of the system. Figure 1 shows the vertical and horizontal sectional views of the seed-blanket ADS.

In the calculations, $\mathrm{Pu}$ and $\mathrm{MA}$ are recovered from the reprocessing scheme assumed in Tsujimoto research [4].
TABLE 1: Fuel composition of thorium and reprocessed fuel.

\begin{tabular}{lc}
\hline Nuclides & Number density (atoms/b-cm) \\
\hline Reprocessed fuel & \\
${ }^{235} \mathrm{U}$ & $4.177 E-07$ \\
${ }^{236} \mathrm{U}$ & $9.462 E-08$ \\
${ }^{237} \mathrm{~Np}$ & $1.332 E-03$ \\
${ }^{238} \mathrm{Pu}$ & $1.605 E-04$ \\
${ }^{239} \mathrm{Pu}$ & $2.587 E-03$ \\
${ }^{240} \mathrm{Pu}$ & $1.149 E-03$ \\
${ }^{241} \mathrm{Pu}$ & $5.154 E-04$ \\
${ }^{242} \mathrm{Pu}$ & $3.306 E-04$ \\
${ }^{241} \mathrm{Am}$ & $9.092 E-04$ \\
${ }^{242} \mathrm{Am}$ & $1.594 E-06$ \\
${ }^{243} \mathrm{Am}$ & $3.607 E-04$ \\
${ }^{243} \mathrm{Cm}$ & $8.384 E-07$ \\
${ }^{244} \mathrm{Cm}$ & $1.037 E-04$ \\
${ }^{245} \mathrm{Cm}$ & $1.224 E-05$ \\
${ }^{246} \mathrm{Cm}$ & $1.311 E-06$ \\
${ }^{16} \mathrm{O}$ & $1.490 E-2$ \\
Thorium fuel & \\
${ }^{232} \mathrm{Th}$ & $2.1641 E-2$ \\
$\mathrm{Gd}$ & $9.2607 E-8$ \\
${ }^{16} \mathrm{O}$ & $4.3282 E-2$ \\
\hline
\end{tabular}

From that, the spent PWR fuel of $45 \mathrm{GWd} / \mathrm{t}$ burnup was reprocessed after 7 years cooling, and $\mathrm{MA}$ and $\mathrm{Pu}$ were recovered using PUREX and MA is enriched for enhanced MA burning. The initial content of thorium and reprocessed fuel is determined in order to achieve the initial $k_{\text {eff }}$ of 0.959 . The isotopic composition of thorium and reprocessed fuel is shown in Table 1. 
TABLE 2: Performance characteristics of the ADS.

\begin{tabular}{lc}
\hline Core diameter $(\mathrm{cm})$ & 280 \\
Core length $(\mathrm{cm})$ & 300 \\
Fuel pin radius $(\mathrm{cm})$ & 0.315 \\
Pin pitch $(\mathrm{cm})$ & 0.89 \\
Cladding thickness $(\mathrm{cm})$ & 0.031 \\
Thorium assemblies/reprocessed fuel assemblies & $84 / 96$ \\
Thorium weight/reprocessed fuel weight & $2.45 / 1$ \\
LBE target radius $(\mathrm{cm})$ & 15.0 \\
Accelerator current $(\mathrm{mA})$ & $13-30$ \\
Spallation yield $(\mathrm{n} / \mathrm{s})$ & 30 \\
Power output $(\mathrm{MW}$ th $)$ & 840 \\
Cycle length $($ days $)$ & 430 \\
Radial power peaking factor at BOC & 2.50 \\
Axial power peaking factor at BOC & 1.21 \\
Radial power peaking factor at EOC & 2.09 \\
Axial power peaking factor at EOC & 1.20 \\
Void coefficient at BOC $\left(\times 10^{-2} \Delta k / k\right)$ & -7.53 \\
Burnup $(\mathrm{GWd} / \mathrm{MT})$ & 40 \\
$k_{\text {eff }}$ & \\
BOC & $0.9591 \pm 0.0012$ \\
EOC & $0.8983 \pm 0.0012$ \\
Burnup reactivity swing & $0.0634 \Delta k$ \\
\hline
\end{tabular}

2.2. Code. MCNPX is an extension of MCNP-4B and LAHET with the improvement of physics simulation models; extension of neutron, proton, and photonuclear libraries to $150 \mathrm{MeV}$; and the formulation of additional variancereduction and data-analysis techniques [5]. MCNPX with ENDF/B-VII.0 library [6] was used for evaluation in this problem. Burnup capability is performed via linked process involving steady-state flux calculations by MCNPX and nuclide depletion calculation by CINDER90 [7]. However, MCNPX is unable to take into account the flux from external source during burnup calculation [2]. Therefore, $k_{\text {eff }}$ and fuel evolution results are obtained under kcode mode approximately. As long as the external source would not be sufficient to drive the system towards criticality, the results are reasonable to discuss the transmutation capability of the system.

\section{Results and Discussion}

3.1. TRU Waste Transmutation. In order to investigate the neutronics characteristics and transmutation potential of the seed and blanket thorium-reprocessed fuel ADS, the MCNPX code was employed for the calculation using the core configuration illustrated in Figure 1. Performance characteristics of the core are shown in Table 2.

Neutron energy spectra for different regions in ADS core are demonstrated in Figure 2. It clearly shows the domination of neutron in the fast energy range. The $3 \mathrm{keV}$ resonance of sodium coolant is the reason to cause the flux "drop" at that region. The fast spectrum system is advantageous for actinide transform since the actinide fission to capture ratio

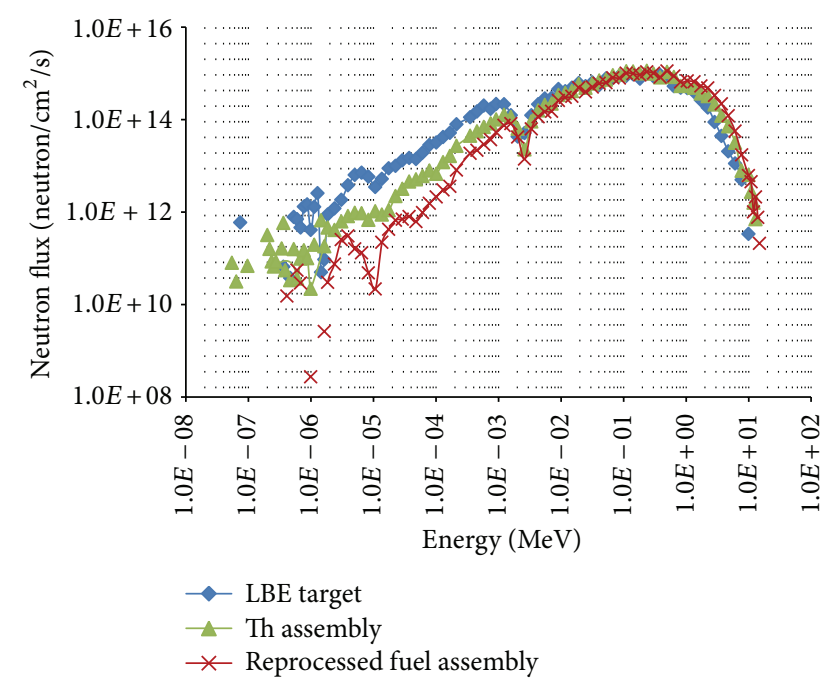

FIGURE 2: Neutron energy spectra for different regions in ADS core.

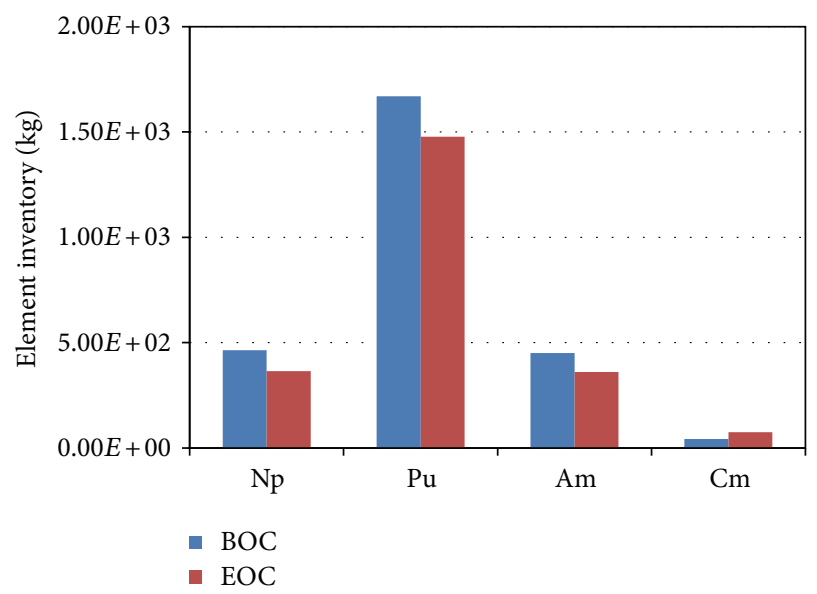

FIGURE 3: Isotopic inventory for $40 \mathrm{GWd} / \mathrm{t}$ fuel burnup.

is higher compared with the thermal system [3]. Therefore, it is more efficient for destructions of actinides while less minor actinide is built up.

The mass evolution is the key parameter to prove the TRU waste transmuting potential of the seed and blanket thoriumreprocessed fuel ADS. Figure 3 shows the element inventory in the $840 \mathrm{MW}_{\text {th }} \mathrm{ADS}$ using thorium-reprocessed fuel for $40 \mathrm{GWd} / \mathrm{t}$ fuel burnup. At the end of cycle (EOC), a significant amount of TRUs is transmuted: $98.5 \mathrm{~kg}$ of neptunium, $192 \mathrm{~kg}$ of plutonium, and $90.5 \mathrm{~kg}$ of americium. The most important contribution accounted for ${ }^{239} \mathrm{Pu}$ (mainly due to fission reaction). The transmutation of ${ }^{237} \mathrm{~Np}$ and ${ }^{241} \mathrm{Am}$ is also important, although a part of it is transformed into ${ }^{238} \mathrm{Pu}$. A small amount of curium is produced $(33 \mathrm{~kg})$.

In order to compare the TRU transmutation capability of different systems, the actinide balances per $\mathrm{TW}_{\text {th }} \mathrm{h}$ in PWR [8], advanced recycling reactor (ARR) [9], and the seed and blanket ADS are summarized in Table 3. Compared with the fast neutron spectrum ARR dedicated for TRU burning and Am transmutation, the seed and blanket ADS shows an 
TABLE 3: Comparison of the actinide balance per ton of $\mathrm{TW}_{\mathrm{th}} \mathrm{h}$ for different systems.

\begin{tabular}{lccc}
\hline $\begin{array}{l}\text { Actinides } \\
\left(\mathrm{kg} / \mathrm{TW}_{\mathrm{th}} \mathrm{h}\right)\end{array}$ & $\begin{array}{c}\mathrm{PWR}(\mathrm{UOX}) \\
41 \mathrm{GWd} / \mathrm{tHM}\end{array}$ & $\begin{array}{c}\text { ARR (spent UO2) } \\
150 \mathrm{GWd} / \mathrm{tHM}\end{array}$ & $\begin{array}{c}\text { Seed and blanket } \\
\text { ADS 40 GWd/ton } \\
\text { of spent fuel }\end{array}$ \\
\hline $\mathrm{Pu}$ & +11.3 & -16.3 & -22.6 \\
$\mathrm{~Np}$ & +1.18 & -2.3 & -11.6 \\
$\mathrm{Am}$ & +1.04 & -13.1 & -10.7 \\
$\mathrm{Cm}$ & +0.03 & +4.0 & +3.9 \\
\hline
\end{tabular}

TABLE 4: Composition of nuclear waste after $50 \mathrm{GWd} / \mathrm{t}$ of heavy metal burnup.

\begin{tabular}{lcc}
\hline Nuclide & $\begin{array}{c}\text { Element } \\
(\mathrm{kg} / \mathrm{GWe} / \mathrm{yr}) \text { at 50 GWd/tHM }\end{array}$ & $\begin{array}{c}\text { Element } \\
(\mathrm{kg} / 8 \text { GWe/yr }) \text { in 2025 }\end{array}$ \\
\hline $\mathrm{U}$ & 20765 & 166120 \\
$\mathrm{~Np}$ & 16.0 & 128 \\
$\mathrm{Pu}$ & 255.2 & 2041.6 \\
$\mathrm{Am}$ & 16.4 & 131.2 \\
$\mathrm{Cm}$ & 1.7 & 13.6 \\
LLFFs & 127.2 & 1017.6 \\
\hline
\end{tabular}

advantage in TRU elimination capability. Besides, the fast reactors are facing the safety problem due to the shorter lifetime of prompt neutron. Also, the fraction of delayed neutron emitted per fission for TRUs is several times smaller than that of ${ }^{235} \mathrm{U}$ and ${ }^{238} \mathrm{U}$. TRU has little or no negative reactivity feedbacks due to Doppler broadening effect in the capture resonances [8]. More attention should be paid to the design of control system of fast reactor in order to achieve the safe operation. Thus, the fast spectrum ADS, which takes advantage of the high fission to capture ratio and has the inherent safety feature of the subcritical system, is a realistic solution for high level waste transmutation.

\subsection{TRU Elimination Strategy for Future Reactors in Vietnam.} The development plan of nuclear power expresses the quick expansion of nuclear power in Vietnam in the near future. By 2027, eight 1000 MWe class reactors are planned to come online. The large amount of nuclear waste from those nuclear power plants will bring serious radiotoxic and proliferation risks. Massive research and development (R\&D) works on how to deal with these hazardous materials are needed to be done and should start from now on.

Regarding the radiotoxicity and decay heat, HLWs which include TRUs and LLFFs are the most hazardous materials. TRUs and LLFFs, respectively, occupy $1.1 \%$ and $0.6 \%$ of the conventional spent nuclear fuel from a LWR. The element masses in the waste for UOX with an initial enrichment of $4.2 \%$, an average thermal burnup of $\sim 50 \mathrm{GWd} / \mathrm{t}$ of heavy metal and after 5 years of cooling time, are demonstrated in Table 4 [8]. Consequently, the amount of waste for $8 \mathrm{GWe}$ by 2027 is easily derived. More than 3 tons of TRUs and LLFFs is produced every year. It will extend to 120 tons of TRUs and LLFFs of which 10 tons is MA after 40 years of average lifetime for a conventional nuclear reactor.

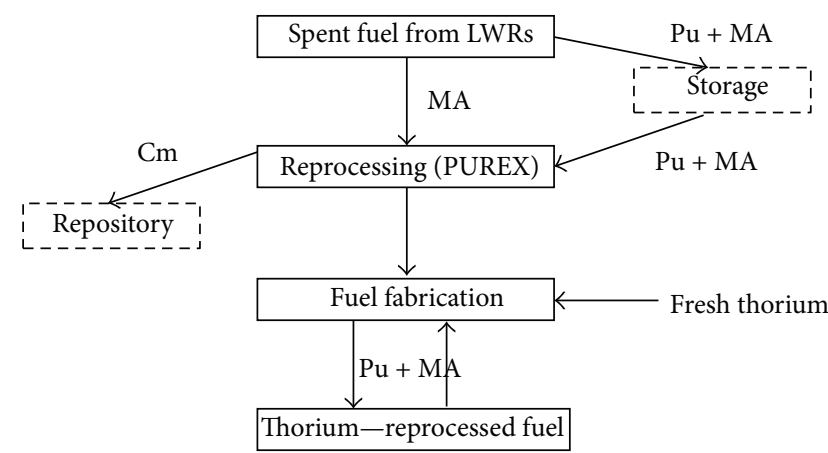

FIgURE 4: Fuel cycle with the ADS utilizing thorium and reprocessed fuel.

Considering the fact that Vietnam is one of the most crowded countries with a small total area (approximately $331.210 \mathrm{~km}^{2}$ ), a permanent geological repository to dispose the HLW is hardly an option. By taking the advantages as discussed previously, thorium-reprocessed fuel ADS is considered as a safe, clean, and economical solution of TRU waste management problem. From the consumption of $\mathrm{Pu}$ and MA of ADS system in Table 3, it implies that each $1 \mathrm{GW}_{\text {th }}$ ADS can be able to transmute the TRU waste from $2 \mathrm{GW}_{\text {th }}$ LWRs. By that it means that 14 units of ADS with $840 \mathrm{MW}$ are required to deal with the waste from those reactors and contribute about $4 \mathrm{GWe}$ ( $40 \%$ thermal efficiency, approximately) to the grid.

Although great amount of validation and verification are needed to be done to finalize the design of the thoriumreprocessed fuel ADS, this study offers a potential solution to solve the TRU waste management in Vietnam. However, not only TRU waste but also LLFFs in the spent fuel of LWRs should be transmuted into stable or short-lived nuclides in order to eliminate the permanent geological repository. The LLFFs could be separated and transmuted in the dedicated facility. One of the options is that it can be loaded in the core reflector of ADS where the thermal neutron spectrum is utilized to transmute those nuclides. This approach is now under estimation and will not be discussed in the scope of this paper.

The proposed fuel cycle with the ADS utilizing thorium and reprocessed fuel is illustrated in Figure 4. Pu and MA from spent fuel after storage for 7 years to reduce the decay heat and short-life radiotoxic isotopes are reprocessed and fabricated for ADS. After being burnt, the spent fuel of ADS can be recovered and put back to the system for further transformation. Because of the proliferation-related issue, the reprocessing included in this cycle may require many political discussions to be approved for the peace used purpose of recovered spent fuel. But this is a clean, safe, economical and sustainable fuel cycle which should be actualized in the near future.

\section{Conclusions}

The seed and blanket thorium-reprocessed fuel ADS core concept was investigated in this study. As confirmed 
previously, besides producing energy, a significant amount of TRUs was transmuted using the seed and blanket thoriumreprocessed fuel ADS. At $40 \mathrm{GWd} / \mathrm{t}$ burnup, $192 \mathrm{~kg}$ of plutonium and $156 \mathrm{~kg}$ of MA can be eliminated. It implies that $1 \mathrm{GW}_{\text {th }}$ ADS can be able to transmute the TRU waste from $2 \mathrm{GW}_{\text {th }}$ LWRs. 14 units of ADS would be required to deal with the TRUs from the future reactors to be constructed in Vietnam and add about 4 GWe (40\% thermal efficiency) to the grid. It is noteworthy that even though the results are approximated, it is reasonable to discuss the transmutation potential of the ADS. This result proposes a promising solution to solve the TRU waste management in Vietnam in the next few decades.

\section{References}

[1] "Nuclear Power in Vietnam," 2013, http://www.world-nuclear.org/info/Country-Profiles/Countries-T-Z/Vietnam/\# .UZ8c4aLE18E.

[2] G. de Paula Barros, C. Pereira, M. A. F. Veloso, and A. L. Costa, "Study of an ADS loaded with thorium and reprocessed fuel," Science and Technology of Nuclear Installations, vol. 2012, Article ID 934105, 12 pages, 2012.

[3] H. R. Trellue, Reduction of the radiotoxicity of spent nuclear fuel using a two-tiered system comprising light water reactors and accelerator-driven systems [Ph.D. thesis], University of New Mexico, 2003.

[4] K. Tsujimoto, T. Sasa, K. Nishihara, H. Oigawa, and H. Takano, "Neutronics design for lead-bismuth cooled accelerator-driven system for transmutation of minor actinide," Journal of Nuclear Science and Technology, vol. 41, no. 1, pp. 21-36, 2004.

[5] D. Pelowitz, Ed., MCNPX User's Manual, Los Alamos National Security, 2011.

[6] M. B. Chadwick, P. Obložinský, M. Herman et al., "ENDF/BVII. 0: next generation evaluated nuclear data library for nuclear science and technology," Nuclear Data Sheets, vol. 107, pp. 29313060, 2006.

[7] W. B. Wilson, S. T. Cowell, T. R. England, A. C. Hayes, and P. Moller, “A Manual for CINDER'90 version 07. 4 Codes and Data," Tech. Rep. LA-UR-07-8412, Los Alamos National Laboratory, 2007.

[8] A. Herrera-Martinez, Transmutation of nuclear waste in accelerator-driven systems [Ph.D. thesis], University of Cambridge, 2004.

[9] K. Ikeda, R. A. Kochendarferb, H. Moriwakia, and S. Kunishimac, "Enhancing TRU and Am transmutation in Advanced Recycling Reactor," Nuclear Engineering Design, vol. 241, no. 5, pp. 1438-1453, 2011. 


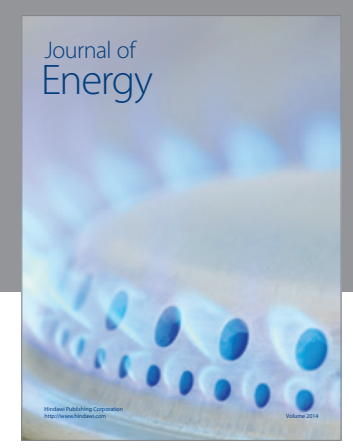

Journal of

Industrial Engineering
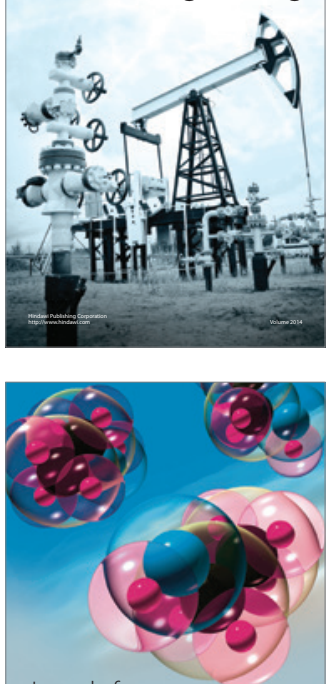

Fuels
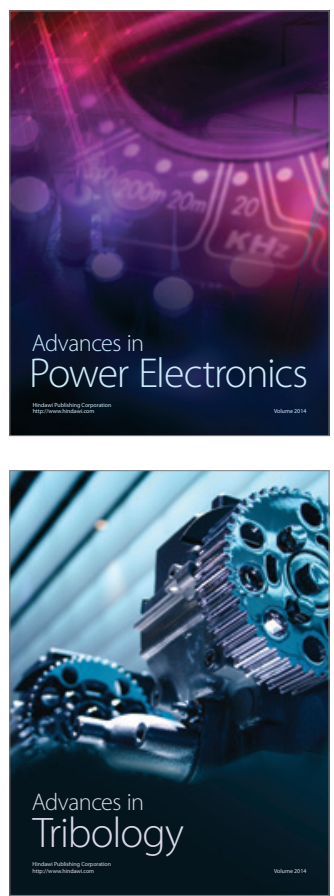

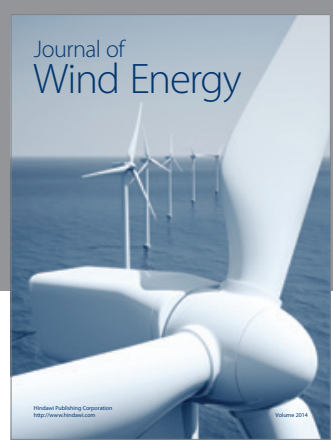

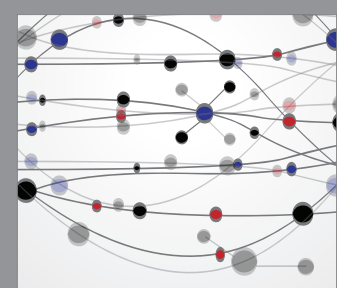

The Scientific World Journal

Submit your manuscripts at http://www.hindawi.com

Journal of

Structures
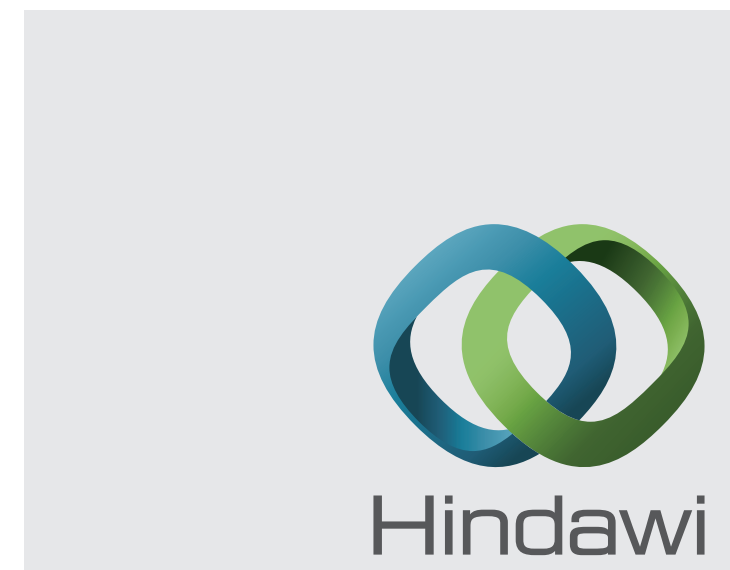

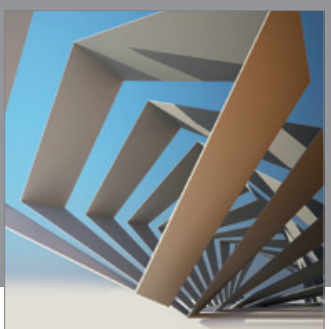

Rotating

Machinery
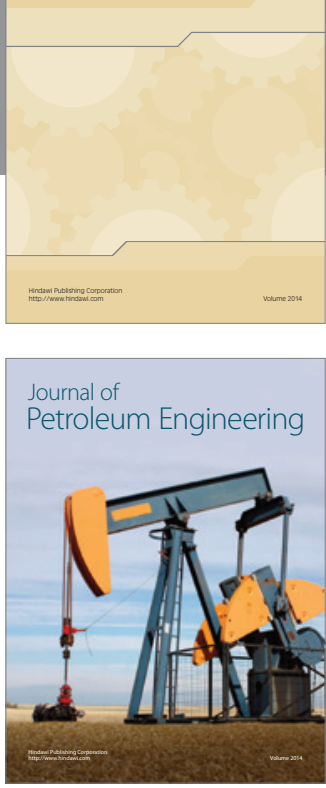

Journal of

Solar Energy
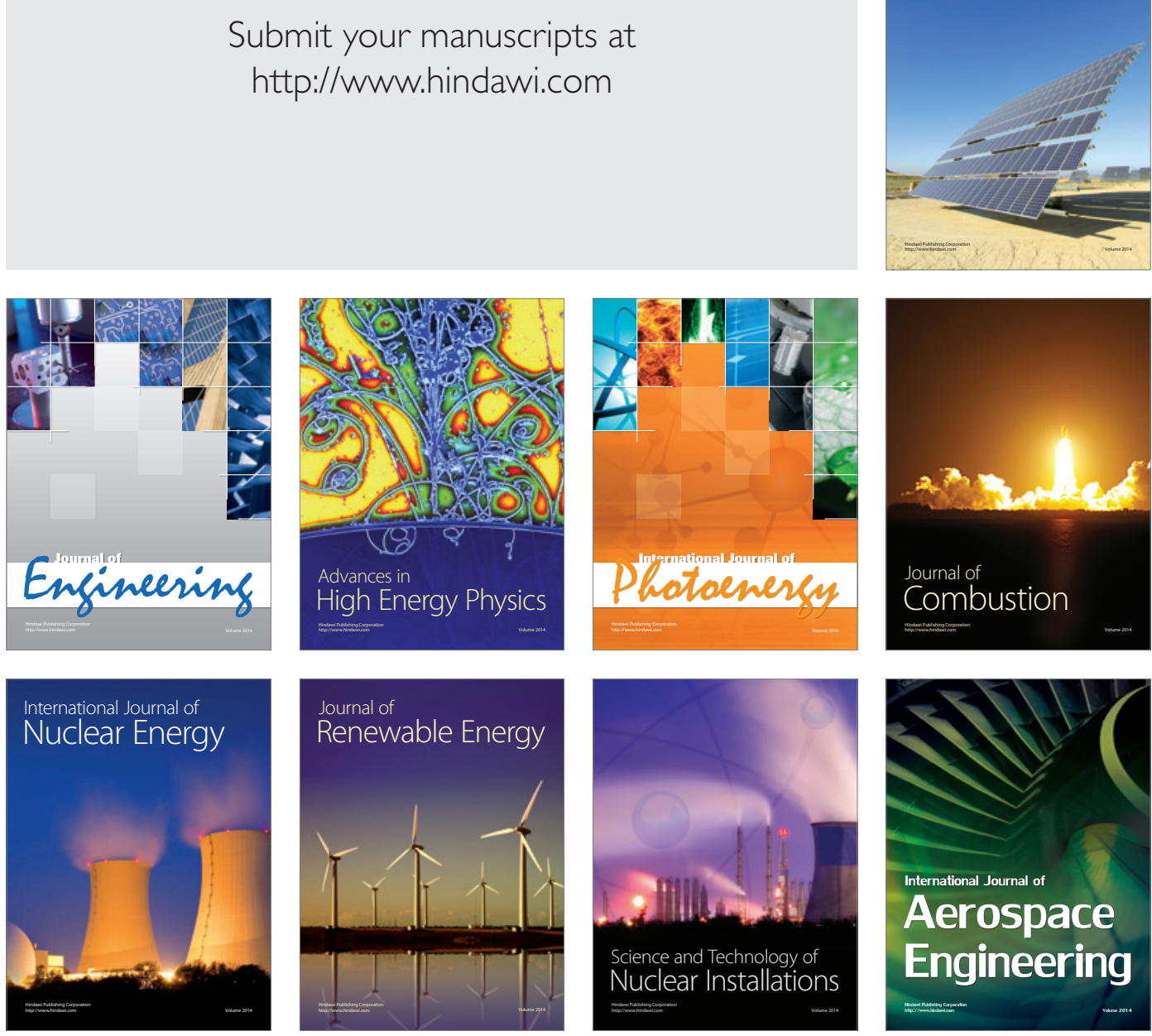